\title{
UTILIDAD DEL PET EN EL DIAGNÓSTICO Y RESPUESTA AL TRATAMIENTO EN UN TUMOR GERMINAL EXTRAGONADAL DE PRESENTACIÓN ATÍPICA
}

J.M. FERNÁNDEZ MONTERO, J.J. ZUDAIRE BERGERA, J. RIOJA, J. REGOJO BALBOA, J. LÓPEZ FERRANDIS, D. SÁNCHEZ ZALABARDO, D. ROSELL COSTA, J.E. ROBLES GARCÍA, J.M. BERIÁN POLO

Departamento de Urología. Clínica Universitaria. Universidad de Navarra.

Actas Urol Esp. 27 (10): 839-842, 2003

\section{RESUMEN}

UTILIDAD DEL PET EN EL DIAGNÓSTICO Y RESPUESTA AL TRATAMIENTO

EN UN TUMOR GERMINAL EXTRAGONADAL DE PRESENTACIÓN ATÍPICA

Los tumores primarios de origen extragonadal son raros, con menos de 1.000 casos descritos en la literatura.

Aunque la incidencia de los TGE (tumores germinales extragonadales) es desconocida, datos clínicos sugieren que constituyen alrededor del 3-5\% de todos los tumores de células germinales.

Presentamos un caso clínico de TGE con una presentación clínica atípica.

Exponemos nuestra experiencia diagnóstica y terapéutica en este tipo de lesiones.

PALABRAS CLAVE: PET. Tumor germinal extragonadal. $\alpha$-FP. $\beta$-HCG.

\section{ABSTRACT \\ PET UTILITY IN THE DIAGNOSTIC AND FOLLOW UP IN ATIPIC PRESENTATION OF EXTRAGONADAL GERM CELL TUMOUR}

Primary tumors of extragonadal origin are rare, with fewer than 1000 cases described in the literature.

Although the exact incidence of EGTs is unknown, clinical data suggest that roughly 3\% to 5\% of all germ cell tumors.

We expouse a case report of EGT with unusually clinic presentation.

We present our diagnostic and terapeutic experience in this injuries.

KEY WORDS: PET. Extragonadal germ cell tumor. $\alpha$-FP. $\beta$-HCG.

L os TGE constituyen una entidad poco frecuente en la práctica clínica (menos de 1.000 casos descritos). La presentación clínica es muy variable, pudiendo a veces pasar desapercibidos y ser un hallazgo casual de una exploración de imagen.

Ocasionalmente el diagnóstico puede plantear dificultades, sobre todo si se trata de tumores germinales seminomatosos, los cuales no expresan $\alpha$-FP y $\beta$-HCG, siendo necesaria la biopsia de la pieza quirúrgica.

Aunque tienen peor pronóstico que los tumores germinales testiculares, hoy día con quimioterapia (pauta BEP) y cirugía, se obtienen altas tasas de supervivencia. 


\section{CASO CLÍNICO}

Varón de 37 años de edad, acude a consulta de traumatología por dificultad en la deambulación y molestias en extremidad inferior derecha de 4 meses de evolución.

Exploración física: hipotrofia de cuadriceps derecho, con disminución de la fuerza. Es diagnosticado de distensión muscular e inicia rehabilitación.

Pasado un mes vuelve a consulta de traumatología con progresión de los síntomas. Se le realiza una resonancia magnética (Fig. 1), observándose una masa sólida retroperitoneal, adherida a una cavidad líquida tabicada en continuidad con el psoas ilíaco derecho y que alcanza el tercio proximal del muslo. El líquido de la cavidad obtenido por punción se demostró estéril y la citología negativa. Los valores séricos de $\beta$-HCG y $\alpha$-FP fueron de $54 \mathrm{UI} / \mathrm{L}$ y $26 \mathrm{UI} / \mathrm{ml}$, respectivamente. La ecografia testicular fue normal.

El PET con 18 FDG objetiva focos compatibles con infiltración ganglionar en cadena inguinal, iliaca, presacra y para-aórtica izquierda (Fig. 2).

Con el presunto diagnóstico de TGE se realiza PAAF de la adenopatía inguinal izquierda. Es informada como carcinoma poco diferenciado compatible con carcinoma embrionario.

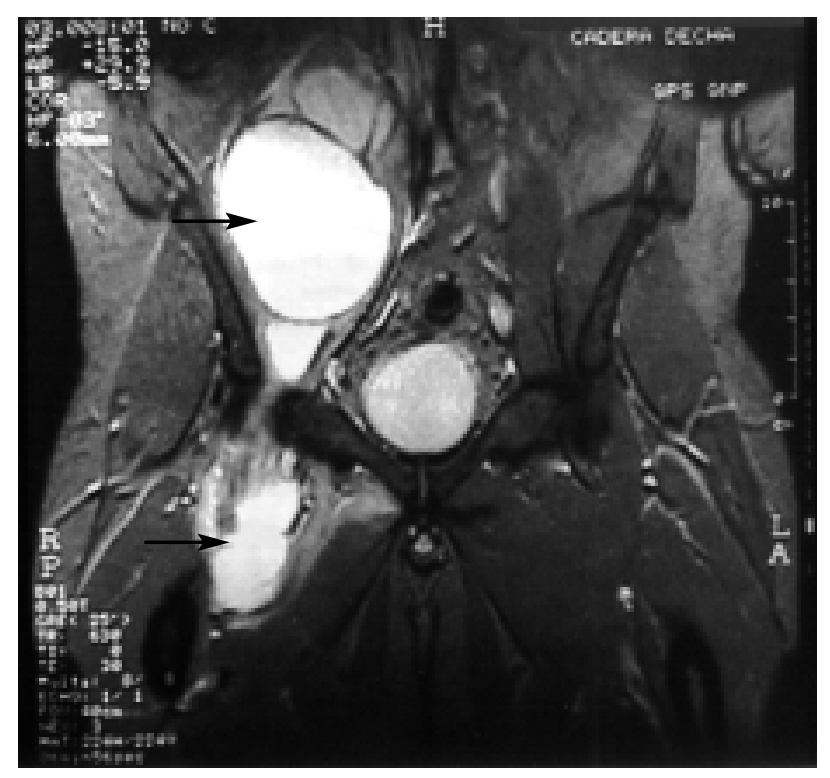

FIGURA 1. Corte coronal, potenciado en T2. Imagen de caracteristicas quisticas de localización retroperitoneal, con un tamaño de 30 por $10 \mathrm{~cm}$, que se continúa en sentido cráneo-caudal, atravesando el conducto inguinal hasta tercio proximal de muslo derecho.

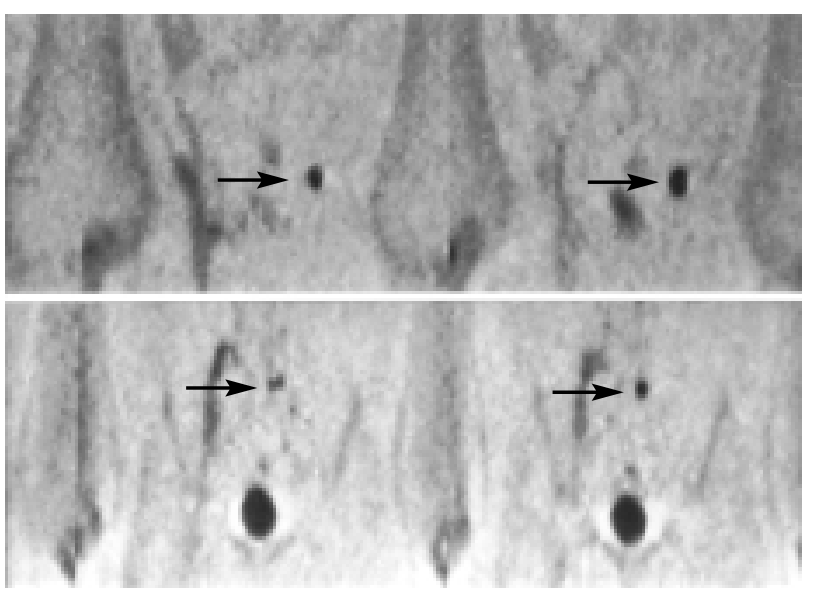

FIGURA 2. Focos compatibles con infiltración ganglionar (flechas).

Resonancia magnética cerebral normal.

Una vez diagnosticado se inicia tratamiento con 4 ciclos de pauta BEP. A la conclusión los marcadores $\beta$-HCG y $\alpha$-FP se normalizaron pero la masa retroperitoneal prácticamente no se había modificado.

El PET post-tratamiento informa de ausencia de captación por parte de la masa retroperitoneal y de normalización del patrón de captación del radiotrazador en las cadenas ganglionares previamente hipercaptantes (Figs. 3a y 3b).

Se plantea el rescate quirúrgico de la masa retroperitoneal que se realiza sin incidentes (Figs. 4 a y $4 b)$.

El informe anatomopatológico indica que la pieza corresponde a un teratoma maduro.

Un año después del tratamiento la $\beta$-HCG y $\alpha$ FP son indetectables y el TAC abdominal no muestra signos de recidiva local.

\section{DISCUSIÓN}

Los TGE son raros, constituyen el 3-5\% de todos los tumores de células germinales.

El origen de los TGE retroperitoneales es muy controvertido. Aunque la explicación más plausible sugiere que proceden de células ectópicas germinales con emigración aberrante en la embriogénesis ${ }^{1}$, algunos autores consideran que son metástasis no visibles (la ecografía testicular es siempre normal) de un tumor testicular primario $^{2}$.

Las localizaciones más frecuentes en orden decreciente son: mediastino, retroperitoneo, región 

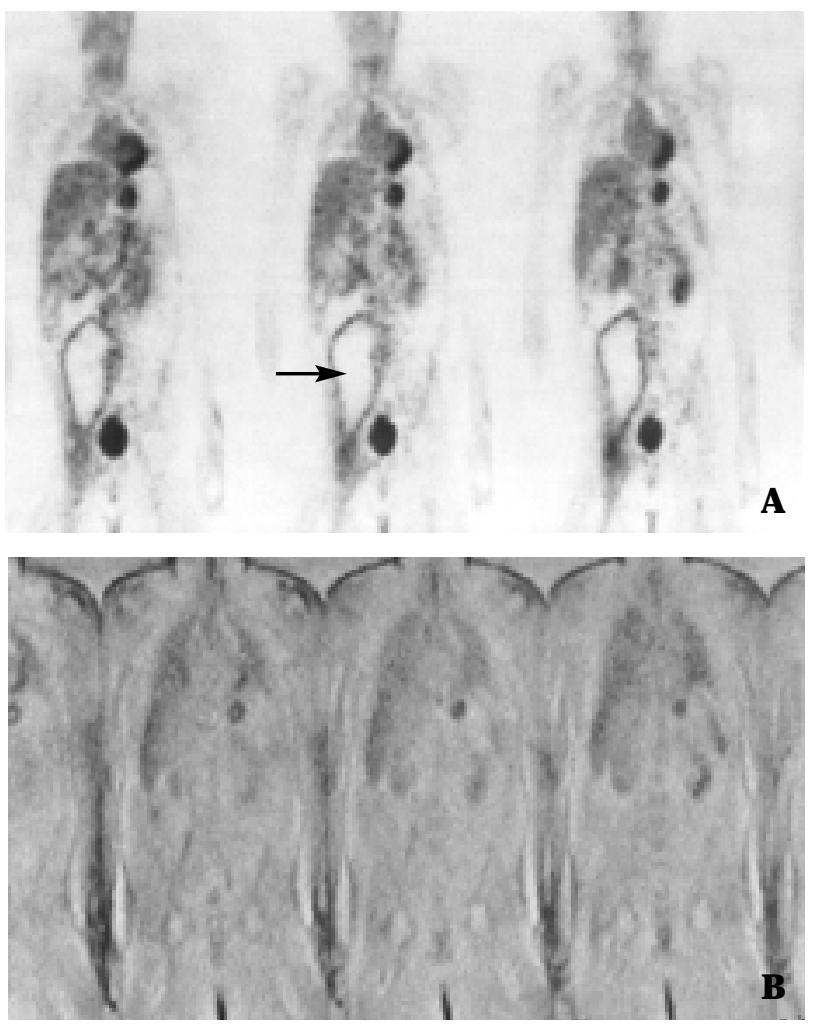

FIGURAS 3A y 3B. PET.

A: PET previo al tratamiento.

B: PET post-quimioterapia.

sacrococcigea y glándula pineal, aunque otros sitios inusuales han sido descritos. Los TGE afectan preferentemente a varones, aunque lesiones de localización sacrococcigea son más frecuentes en mujeres y niños.

La presentación clínica más común de los TGE de localización retroperitoneal consiste en dolor abdominal o lumbar, masa palpable, obstrucción vascular, pero es relativamente frecuente que pasen desapercibidos sin dar ningún tipo de sintomatología.

Nuestro paciente tuvo una presentación clínica atípica enmascarada por un cuadro que hacía sospechar de un origen traumatológico de la cojera.

Otro aspecto peculiar es la presentación quística de la masa, con citología negativa tanto para malignidad como para infección.

La utilización de PET en el estudio de extensión y sobre todo seguimiento en tumores germinales es cada vez más extensa. En el caso que comentamos ha evidenciado actividad donde la RMN no lo había hecho. La masa retroperitoneal no capta ni antes ni después de la quimioterapia lo que sugiere la presencia de teratoma. Hoy en día el PET puede ser muy útil en el diagnóstico y seguimiento de los tumores germinales porque es capaz de detectar actividad tumoral en lugares aparentemente normales con TAC y de valorar la viabilidad de tejidos residuales post-quimioterapia ${ }^{3-6}$.

En algunas ocasiones, la no expresión de $\alpha$-FP y $\beta$-HCG, hace difícil el diagnóstico etiológico de estas masas, y tenemos que esperar a la pieza quirúrgica para programar un tratamiento quimioterápico correcto ${ }^{7}$.

En nuestro caso, el diagnóstico anatomopatológico se hizo mediante biopsia de adenopatía inguinal.

La actitud terapéutica de este tipo de tumores ha variado mucho a lo largo del tiempo.

Pacientes con tumores no seminomatosos retroperitoneales primarios tenían una pobre respuesta a la quimioterapia ${ }^{8,9}$, en contraste con la buena respuesta de los seminomatosos ${ }^{10}$. Sólo 2 de los 18 pacientes tratados en el Memorial Sloan
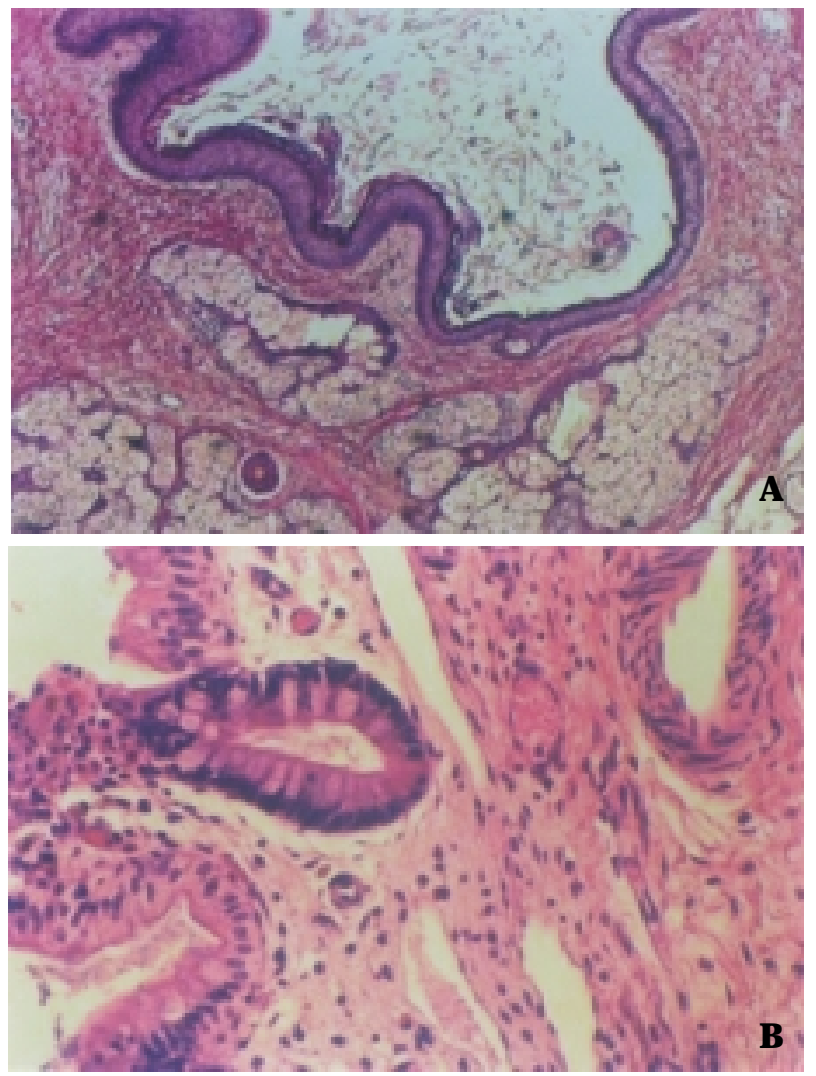

FIGURAS 4A y 4B. Anatomía patológica.

A: Piel, con folículos pilosebáceos y glándulas sudoriparas. B: Tejido similar a intestino delgado. 
Kettering a principios de los 80 con sucesivos protocolos de VAB tuvieron una remisión completa, aunque Garnick y cols. (1983) publicaron mismos resultados ${ }^{11}$, Hainswork y cols. (1982), usando la pauta PVB consiguieron un índice de respuesta mayor ${ }^{12}$.

Según autores el abordaje terapéutico de este tipo de tumores se puede enfocar de diferentes maneras, algunos optan por la resección quirúrgica como primer paso en enfermedad localizada y quimioterapia para la enfermedad residual o metastásica, sobre todo si se trata de niños y adolescentes.

Pero en la actualidad el criterio de clasificación y tratamiento de estos pacientes sigue las pautas de "International Germ Cell Cancer Collaborative Group (IGCCCG)", que tras dos reuniones consenso estableció una clasificación pronóstica de todos los tumores germinales en $1997^{13}$. De acuerdo con este criterio nuestro paciente se incluye en el grupo de buen pronóstico en el que la supervivencia esperada es del $92 \%$. Es claro actualmente que la localización retroperitoneal primaria no altera el pronóstico a diferencia del tumor primario mediastínico ${ }^{14,15}$, que en la clasificación se incluye de entrada en el grupo de mal pronóstico.

El tratamiento consiste en 3 ó 4 ciclos de quimioterapia (Pauta BEP), con resección quirúrgica de la posible masa residual ${ }^{14}$.

Es bien conocido que en tumores de células germinales, cuando hay masa residual tras quimioterapia en el 30-40\% de los casos es teratoma maduro, en el $30-40 \%$ de los casos fibrosis y en el $20-30 \%$ tumor viable. La presencia de teratoma maduro sugiere que o bien algunas células se diferencian con quimioterapia o probablemente a que formaban parte del tumor y son resistentes, por su benignidad, a la quimioterapia. Nuestro caso indica que el componente fundamental era teratoma maduro y que la quimioterapia eliminó toda célula maligna.

\section{CONCLUSIÓN}

Los TGE incluidos en el grupo de buen pronóstico, tienen una buena respuesta a la pauta BEP, la cirugía de rescate es una buena opción terapéutica, y existe una correlación entre marcadores tumorales negativos y negatividad del PET, siendo este último un buen método diagnóstico para valoración de extensión de enfermedad.

\section{REFERENCIAS}

1. DOMINIK T. SCHNEIDER, AMY E et al.: Multipoint imprinting analysis indicates a common precursor cell for gonadal and nongonadal pediatric germ cell tumors. Cancer Res 2001; 61: 7268-7276.

2. SCHOLZ M, ZEHENDER M, THALMANN GN, BORNER M, THONI H, STUDER UE.: Extragonadal retroperitoneal germ cell tumor: evidence of origin in the testis. Ann Oncol 2002 jan; 13 (1): 121-124.

3. SÁNCHEZ ZUDAIRE JJ, FERNÁNDEZ JM.: 18F-fluoro2-deosyglucose-positron emission tomography in the evaluation of nonseminomatous germ cell tumours at relapse. BJU International 2002; 89: 912-916.

4. HAIN SF, O`DOHERTY MJ, TIMOTHY AR et al.: FDG $\mathrm{PET}$ in the evaluation of germ cell tumours at relapse. Br $J$ Cancer 2000; 83: 863-869.

5. STHEPHENS AW, GOÑI R, HUTCHINS GD, EINHORN LH.: PET evaluation of residual radiographic abnormalities in postchemotherapy germ cell tumour patients. $J$ Clin Oncol 1996; 14: 1637-1641.

6. SUGARAWA Y, ZASANDY KR, GROSSMAN HB et al.: Germ cell tumor. Differentiation of viable tumor, mature teratoma, and necrotic tissue with FDG PET and kinetic modeling. Radiology 1999; 210: 294-296.

7. LASSMANN J, WILE A, WIECHEN K, TAUPITZ M, LOENING SA.: Diagnostic difficulties before definitive treatment of an extragonadal retroperitoneal germ cell tumor. Urology 2001 aug; 58 (2): 281.

8. RECONDO J, LIBSHITZ HI.: Mediastinal extragonadal germ cell tumors. Urology 1978: 11: 369.

9. REYNOLDS TF, TAGODA A, VUGRIN D, GOLBEY RB.: Chemotherapy of mediastinal germ cell tumor. Semin Oncol 1979; 6: 113.

10. STANTON GF, BOSL GJ, VUGRIN D et al.: Treatment of patients with advanced seminoma with cyclophosphamide, bleomycin, actinomycin $\mathrm{D}$, vinblastine and cis-platin (VAB-6). (Abstract C-551). Proc Am Soc Clin Oncol 1983; 2: 1 .

11. GARNICK MB, CANELLOS GP, RICHIE JP.: Treatment and surgical staging of testicular and primary extragonadal germ cell cancer. JAMA 1983; 250: 1733-1741.

12. HAINSWORTH JD, EINHORN LH, WILLIAMS SD et al.: Advanced extragonadal germ cell tumor: successful treatment with combination chemotherapy. Ann Intern Med 1982; 97: 7 .

13. International Germ Cell Consensus Classification: a prognostic factor- based staging system for metastatic germ cell cancers. International Germ Cell Cancer Collaborative Group. JCO 1997; 15: 594-603. [Abstract]

14. BOKEMELLER, CARSTEN, NICHOLS et al.: Extragonadal germ cell tumor of the mediastinum and retroperitoneum: results from an international analysis. $J$ Clin Oncol 2002 apr 1; 20 (7): 1864-1873.

15. BASSETTO MA, PASINI F, FRANCESCHI T, MUUSTACCHI G, CETTO GL.: Extragonadal germ cell tumor: a clinical study. Anticancer Res 1995 nov-dec; 15 (6B): 2751-2754.

Dr. J.M. Fernández Montero

Departamento de Urología. Clínica Universitaria

Apartado 4209

31080 Pamplona

(Trabajo recibido el 7 febrero de 2003) 